\title{
Study of Neurocognitive correlates of Schizotypy Personality Clusters in healthy individuals
}

\author{
M. Carmen Aguilera Ruíz* \\ Neus Barrantes-Vidal ${ }^{\star, \star *}$ \\ Marc Guitart* \\ Lourdes Fañanás*
}

* Unitat d'Antropologia, Departament de Biologia Animal, Facultat de Biologia, Universitat de Barcelona, Barcelona

** Departament de Psicologia Clínica i de la Salut, Facultat de Psicologia, Universitat Autònoma de Barcelona, Barcelona

SPAIN

\begin{abstract}
Background and Objectives: Inconsistencies in the relationship between schizotypy dimensions and neurocognitive functions found in correlational studies may be clarified with the use of alternative methodological approaches. The aim of this study was to examine the existence of different profiles of schizotypal traits and their neurocognitIve correlates in non-clinical subjects by means of cluster analysis.

Methods: We examined seventy six healthy adults from the general population with a comprehensive neurocognitive battery and a schizotypal personality self-report.

Results: Four neurocognitive factors were extracted: visuospatial, semantic evocation, verbal memory, and set-shifting. A three cluster model yielded the following clusters: "lowschizotypy", "positive schizotypy", and "negative/disorganized schizotypy". The positive and negative/disorganized schizotypy clusters showed poorer performance on semantic evocation compared with the low schizotypy cluster.

Conclusions: We found different patterns of specific schizotypy features in a healthy adult community sample and these clusters presented differential performance in relation with the ability to evoke semantic information.
\end{abstract}

Received 6 June 2007

Revised 20 September 2007

Accepted 20 October 2007 


\section{Introduction}

Schizotypy is a personality dimension that comprises cognitive-perceptual unusual experiences, as well as motivational, affective, social and behavioural oddities ${ }^{1}$. Schizotypy is a phenotype hypothesized to result from the psychobiological organization underlying the risk for schizophrenia ${ }^{2}$. In the last years, the study of schizotypy has become an important tool for the research on the aetiology of schizophrenia spectrum, given that studying schizophrenic patients makes it difficult to disentangle the impact of confounding variables such as the presence of psychotic symptoms and the effects of antipsychotic drugs.

Factor analytic studies of schizotypy traits have shown at least three components: negative, positive and disorganization dimensions $^{3-8}$. Similarly, factor analytic studies in schizophrenia have reliably shown that psychotic symptoms can be grouped into positive, negative and disorganization dimensions ${ }^{9-15}$. Although factor analytic studies have provided information about the dimensional structure of schizophrenia and schizotypy based on the interrelationships between measures, they do not give us information about how subjects might be grouped according to their responses in the schizophrenia/schizotypy measures ${ }^{16}$.

Despite of the value of cluster analysis, there have been few cluster analytic studies in schizotypy (see Table I), with the number of clusters yielded ranging from 3 to 4 clusters ${ }^{16-20}$. The inspection of Table I reveals that the most replicated clusters are "low schizotypy", "positive schizotypy", and "negative schizotypy". A "cognitive disorganization" cluster appears only in some studies or it is found associated with negative or positive features, mostly depending on whether specific measures of this construct were actually included in the studies. Finally, some studies found clusters with mixed features of varying levels of intensity ("high schizotypy" or "average schizotypy" cluster). Similarly, in schizophrenia three consistent clusters emerge based on a specific profile of symptoms: one predominantly positive, a second one predominantly negative, and a third one with high scores on both dimensions (positive and negative) ${ }^{21-28}$.

A general pattern of neurocognitive deficits has been found in schizophrenia patients, with attention, memory, and executive functions showing the greatest magnitude of impairment $^{29-32}$. Some studies have tried to understand such heterogeneity by relating cognitive performance to the clinical dimensions of schizophrenia. However, although the negative and disorganized dimensions have been overall more closely associated with poorer performance in memory and executive functions, there is no specific pattern of associations that can be consistently replicated across studies ${ }^{33}$.

The same inconsistencies described for schizophrenia have been found in schizotypy $^{34}$. These discrepancies may be due to the fact that correlational analyses do not give us information about how subjects might be grouped according to their responses in the schizophrenia/schizotypy measures. Therefore, we hypothesized that natural groupings in schizophrenia/schizotypy, based on cluster analysis, and may be more strongly related with specific neurocognitive profiles than schizophrenia/schizotypy dimensions. However, cluster analytic studies relating cognition and schizophrenia/schizotypy are rare. Suhr and Spitznagel ${ }^{34}$ found in a selected sample (only high scorers on schizotypy) that the cluster with predominantly negative schizotypy performed worse than all the remaining clusters on the Wisconsin Card Sorting Test (WCST), a measure of executive functioning. Likewise, Barrantes-Vidal et al. ${ }^{17}$ 


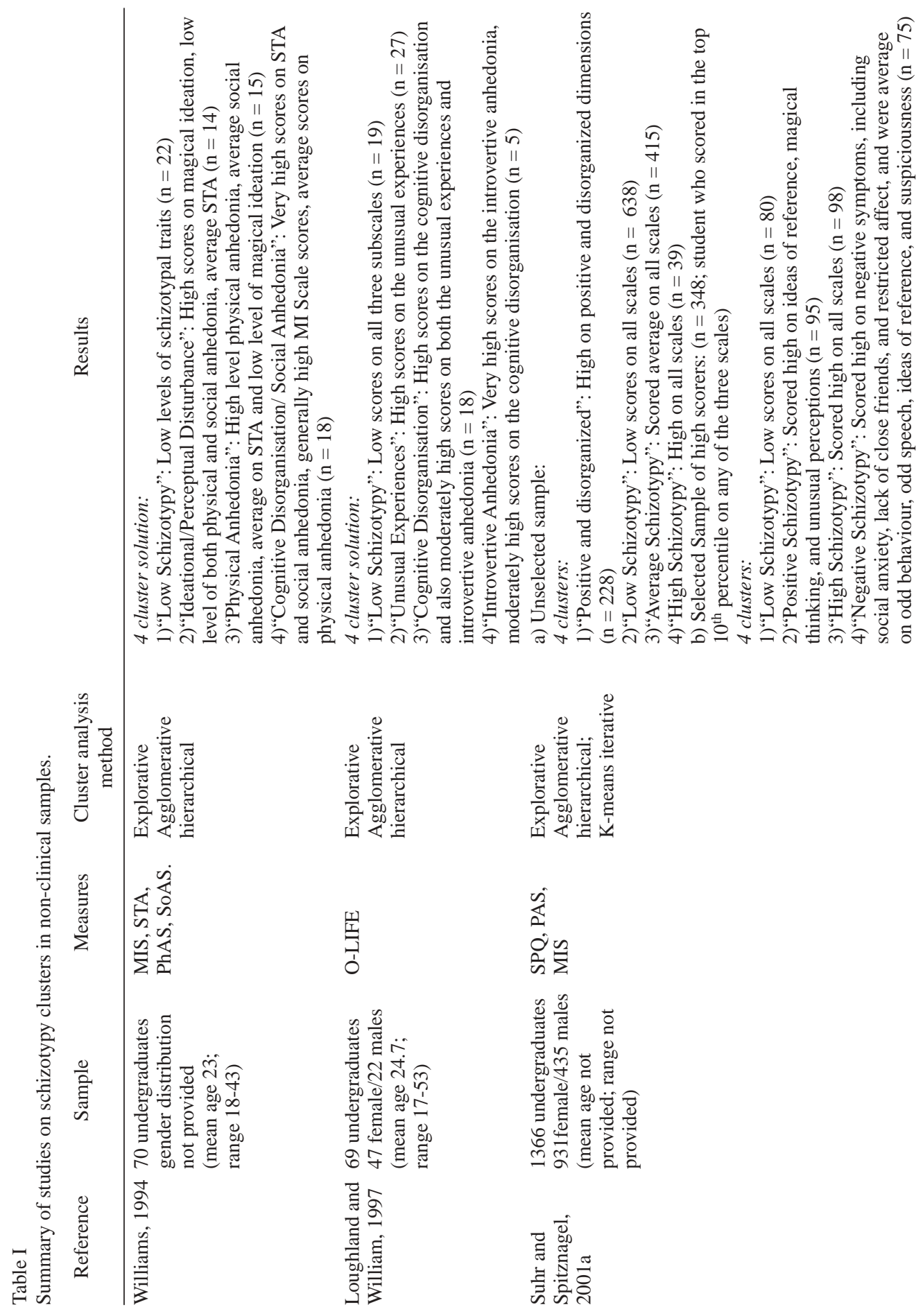




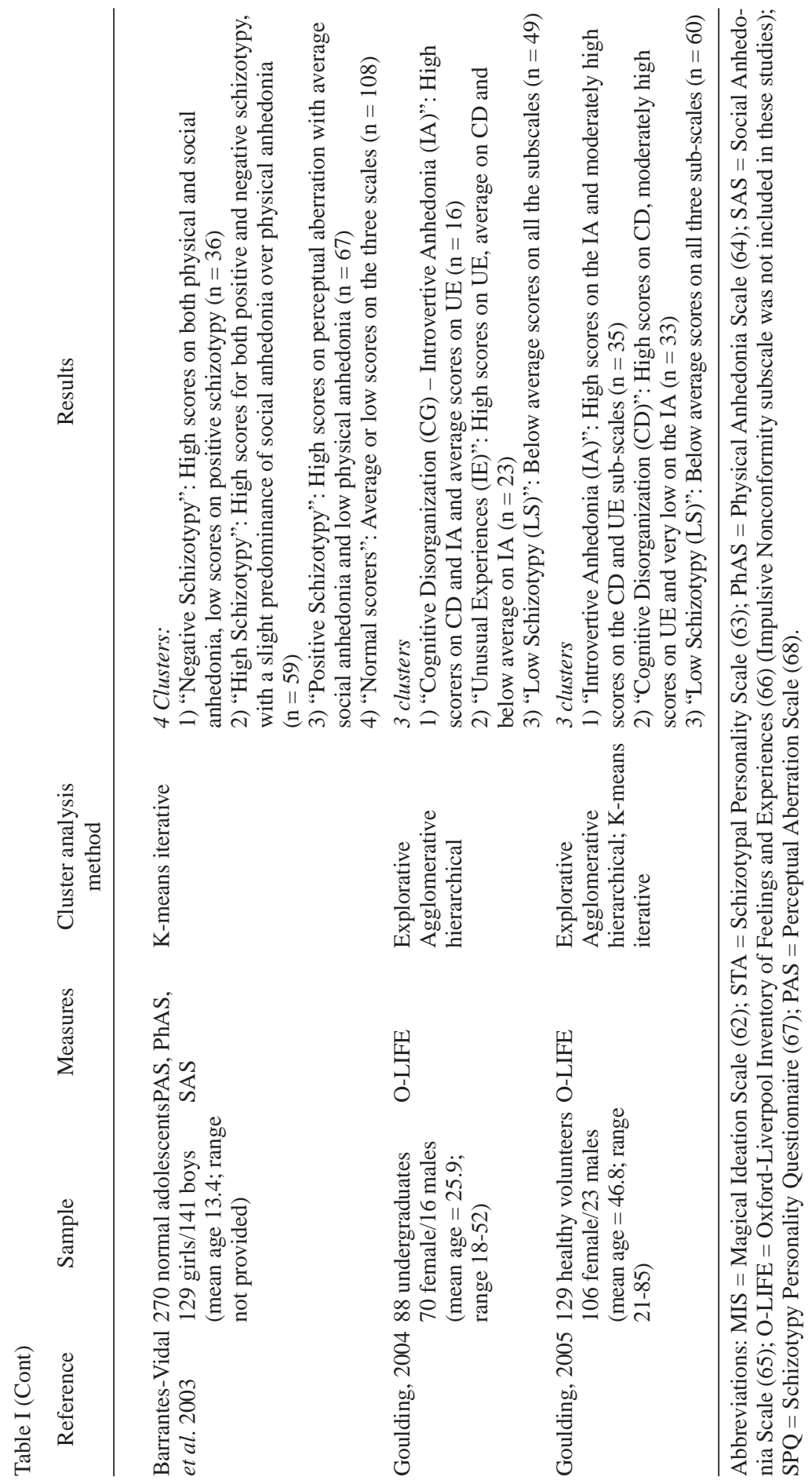


found poorer performance in an attentional task for the "high schizotypy" cluster (i.e, high on both positive and negative dimensions), and worst scores on the WCST for the "negative schizotypy" cluster.

The aims of this study were, first, to explore the presence of different schizotypy profiles in a non-clinical adult sample by means of cluster analysis. Secondly, to compare the relationship between schizotypy and neurocognition as examined by correlating the schizotypy dimensions with neurocognitive functions, and comparing schizotypy clusters on neurocognitive functions. We hypothesized that there would be meaningful variation in schizotypy scores and sound clusters in a general population sample, and that different profiles of schizotypy personality would contribute to explain the heterogeneity of neurocognitive functioning in such nonclinical sample. Specifically, we predicted that a cluster of high scorers (subjects scoring high on several schizotypy dimensions) or with predominant negative features would perform worse on the neurocognitive tests.

\section{Method}

\section{Participants}

Ninety healthy participants completed a comprehensive neurocognitive battery (44 females; mean age $=32.5, \mathrm{SD}=10.8$; range 20-64); mean years of education $=15.4, \mathrm{SD}=$ 3.8). Of these ninety individuals, usable schizotypy questionnaires were available for seventy six (40 females; mean age = $31.9, \mathrm{SD}=10.2$; range $20-64$; mean years of education $=15.7, \mathrm{SD}=3.7$ ).

Participants were recruited from the community through advertisements placed at several university offices and community voca- tional and technical schools from the metropolitan area of Barcelona. All participants provided written informed consent. Exclusion criteria were: i) presence of Cluster A or Borderline Personality Disorder assessed by Structured Clinical Interview for DSM-IV Personality Disorder (SCID-II ${ }^{35}$ ) ii) presence of any past or major psychiatric disorder; iii) presence of any diagnosis of psychosis or any severe mental disorder in first degree relatives assessed by means of the "Family Interview for Genetics Studies" (FIGS ${ }^{36}$ ).

\section{Measures}

Estimated general intelligence was assessed by Block Design (BD) and Information (I) subtests of the Wechsler Adult Intelligence Scale-III (WAIS-III ${ }^{37}$ ). Logical Memory (LM), immediate and delayed, of the Wechsler Memory Scale Revised (WMS-R ${ }^{38}$ ) was used to assess verbal memory. Visual attentional span and working memory functions were evaluated by the Visual Memory Span (VMS) forward and backward of the WMSR. D'shapes and d'numbers indices of the Continuous Performance Test-Identical Pairs version $\left(\mathrm{CPT}-\mathrm{IP}^{39}\right.$ ) were used to assess sustained attention. Moreover, phonemic verbal fluency was measured with the Controlled Oral Word Association test $\left(\mathrm{COWA}^{40}\right.$ and semantic verbal fluency with the Animal Naming $\left(\mathrm{AN}^{41}\right)$. Finally, executive functions were assessed by the perseverative errors (PE) and total correct (TC) indices of the Wisconsin Card Sorting Test $\left(\mathrm{WCST}^{42}\right.$ ).

Schizotypy was measured with the Schizotypy Personality Questionnaire-Brief $\left(\mathrm{SPQ}-\mathrm{B}^{43}\right)$. This self-report questionnaire assesses negative or interpersonal, positive or cognitive-perceptual and disorganized schizotypy dimensions. Following the authors' recommendation, we used the complete scale 
for the disorganization dimension (the abbreviated version of the disorganized dimension obtained unsatisfactory reliability indices) along with the short version of the positive and negative dimensions.

\section{Statistical analysis}

A factor analysis with the twelve individual test scores described was performed to reduce the number of neurocognitive variables for subsequent analysis in the sample of 90 participants. The analysis was carried out using a principal components factor analysis with varimax rotation.

An agglomerative hierarchical cluster analysis using Ward's procedure was performed on the three schizotypy scales. Cluster analysis is a multivariate technique which aims at assembling objects (personality profiles in this case) based on the characteristics that they possess, that is, delineating "natural" groups in the data themselves. First, similarity between groups is defined by their proximity (euclidean distance), next step consisted of forming cluster solution by means of hierarchical procedure (it moves in a stepwise fashion to form an entire range of cluster solutions) and using an agglomerative method (clusters are formed by the combination of existing clusters). Finally, visual inspection of the dendrogram plot and the values of the fusion coefficient may support the cluster solution selected. Then, a multivariate analysis of variance (MANOVA) was conducted using the cluster solution assignment as the independent variable and the schizotypy scores as the dependent variables, in order to obtain a discriminative index for the clusters created.

Finally, an univariate analysis of variance (ANOVA) and correlational analysis were carried out to test the specific relationship between schizotypic clusters and neurocog- nitive domains. The association between schizotypy and neurocognition was conducted with 76 participants. All results are presented with two-tailed levels of significance.

\section{Results}

\section{Data Reduction of Neurocogni- tive Tests}

Four factors were extracted with an eigenvalue of 1 or greater, which explained $71.1 \%$ of the total variance; the amount of variance accounted for by each factor can be seen in Table II. The first factor was named "visuospatial" because all the measures loading in this factor (Forward and Backwards VMS, BD, CPT-IP D'Shapes and D'Numbers) require visuospatial abilities for their performance. The second factor, which consisted of measures of verbal fluency (semantic and phonemic) and I (WAIS-III), was labeled "semantic evocation". The third one was called "verbal memory", because it was constituted by immediate and delayed VM (WMS-R); and the fourth factor was labeled "set-shifting", as it was formed by the PE (with negative loading) and the TC from the WCST.

\section{Cluster Analysis of Schizotypy Variables}

Visual inspection of the dendrogram plot and the values of the fusion coefficient supported a three cluster solution. Wilks' Lambda $(\lambda=0.14)$ was significant $(\mathrm{p}<0.0001)$, explaining $86 \%$ of the total variability. Therefore, a three-cluster model was retained (see Table III). Cluster 1 consisted of 48 subjects (25 females; mean age $=31.4, \mathrm{SD}=9.5$; mean years of education $=16.3, \mathrm{SD}=3.2$ ) and reflected low scores on all schizotypy dimen- 
Table II

Factor Analysis of neurocognitive tests in non-clinical individuals $(\mathrm{n}=90)$.

\begin{tabular}{|c|c|c|c|c|}
\hline \multirow[t]{2}{*}{ Neurocognitive measures } & \multicolumn{4}{|c|}{ Factors } \\
\hline & Visuospatial & $\begin{array}{l}\text { Semantic } \\
\text { evocation }\end{array}$ & $\begin{array}{c}\text { Verbal } \\
\text { memory }\end{array}$ & $\begin{array}{c}\text { Set - } \\
\text { shifting }\end{array}$ \\
\hline Forward Visual Memory Span WMS-R & 0.796 & $*$ & 0.188 & $*$ \\
\hline Backwards Visual Memory Span WMS-R & 0.819 & $*$ & 0.283 & $*$ \\
\hline Block Design WAIS-III & 0.780 & 0.148 & $*$ & \\
\hline D' Shapes CPT-IP & 0.675 & 0.360 & $*$ & 0.194 \\
\hline D' Numbers CPT-IP & 0.578 & 0.448 & $*$ & 0.216 \\
\hline Phonemic fluency & $*$ & 0.862 & $*$ & $*$ \\
\hline Information WAIS-III & 0.224 & 0.701 & 0.181 & $*$ \\
\hline Semantic fluency & 0.214 & 0.651 & 0.349 & 0.115 \\
\hline Immediate logical memory WMS-R & 0.205 & 0.189 & 0.902 & 0.178 \\
\hline Delayed logical memory WMS-R & 0.132 & 0.223 & 0.914 & $*$ \\
\hline Perseverative errors WCST & -0.397 & -0.190 & -0.144 & -0.702 \\
\hline Total Correct WCST & $*$ & $*$ & $*$ & 0.882 \\
\hline$\%$ Explained variability & $25.2 \%$ & $17.8 \%$ & $16.3 \%$ & $11.8 \%$ \\
\hline
\end{tabular}

${ }^{a}$ These are varimax rotated principal components.

*Absolute values below 0.10 .

Abbreviations: WAIS: Weshler Adult Intelligence Scale; WMS-R: Weschler Memory Scale-Revised; CPT-IP: Continous Performance Test- Identical Pairs version; WCST: Wisconsin Card Sorting Test.

sions (positive, negative and disorganized). It was named "Low Schizotypy". Cluster 2 was formed by 10 subjects $(8$ females; mean age $=$ $33.1, \mathrm{SD}=8.5$; mean years of education $=$ 14.3, $\mathrm{SD}=4.3$ ). This cluster showed low scores on negative and disorganized dimensions, but high scores on the positive dimension. It was labeled "Positive Shizotypy". The third cluster was composed of 18 participants (7 females; mean age $=32.8 .7, \mathrm{SD}=12.9$; mean years of education $=14.8, \mathrm{SD}=4.4)$. It showed intermediate scores on the positive dimension and high scores on the negative and disorganized dimensions, and it was called "Negative-Disorganized Schizotypy". No significant differences were found for age $(F=$ $0.18, \mathrm{p}=0.83)$, years of education $(F=2.09, \mathrm{p}$ $=0.13)$ or sex $\left(\chi^{2}=4.37, \mathrm{p}=0.11\right)$ between the three clusters.

Table III

Descriptive data of the schizotypy dimensions ( $\mathrm{Z}$ scores) for each cluster and MANOVA results with a posteriori contrasts (Least Significant Differences).

\begin{tabular}{lccccccc} 
Schizotypy factors & $\begin{array}{c}\text { Cluster 1 } \\
\mathrm{n}=48 \\
\text { Low } \\
\text { Schizotypy }\end{array}$ & $\begin{array}{c}\text { Cluster 2 } \\
\mathrm{n}=10 \\
\text { Positive } \\
\text { Schizotypy }\end{array}$ & $\begin{array}{c}\text { Cluster } 3 \\
\mathrm{n}=18 \\
\text { Negative/ } \\
\text { disorganized } \\
\text { Schizotypy }\end{array}$ & $\mathrm{F}$ & $\mathrm{p}$ & & LSD \\
& & & & & \\
\hline Negative or interpersonal & $-0.37(0.69)$ & $-0.28(0.91)$ & $1.17(0.87)$ & 27.5 & $<0.0001$ & $3>2=1^{\text {a }}$ \\
Disorganized & $-0.39(0.52)$ & $-0.54(0.33)$ & $1.35(1.03)$ & 50.1 & $<0.0001$ & $3>2=1^{\text {b }}$ \\
Positive or cognitive-perceptual & $-0.57(0.29)$ & $1.51(0.75)$ & $0.68(1.05)$ & 61.5 & $<0.0001$ & $2>3=1^{\text {c }}$ \\
\hline
\end{tabular}

${ }^{a}$ Cluster 1 not differ from $2(p=0.72)$, but differ from $3(\mathrm{p}<0.0001)$, cluster 2 different from $3(\mathrm{p}<0.0001)$.

${ }^{b}$ Cluster 1 not differ from 2 ( $\left.\mathrm{p}=0.54\right)$, but differ from 3 ( $\left.\mathrm{p}<0.0001\right)$, cluster 2 different from $3(\mathrm{p}<0.0001)$.

${ }^{c}$ All clusters significantly different at $\mathrm{p}<0.0001$.

Abbreviation: LSD means Least Significant Differences. 
Neurocognitive Performance and Schizotypy

Statistical significance was found only for the semantic evocation factor $(F=4.7 ; \mathrm{p}=$ 0.012) (see Figure 1). A posteriori analysis carried with the Least Significant Differences method indicated that the positive and the negative-disorganized clusters performed sig- nificantly worse compared with the low schizotypy cluster $(\mathrm{p}=0.032$ and $\mathrm{p}=0.01$ respectively). No statistical differences were found between the negative-disorganized and the positive clusters $(\mathrm{p}=0.97)$.

Negative and positive schizotypy dimensions only correlated significantly (inversely) with the "semantic evocation" factor (see Table IV).

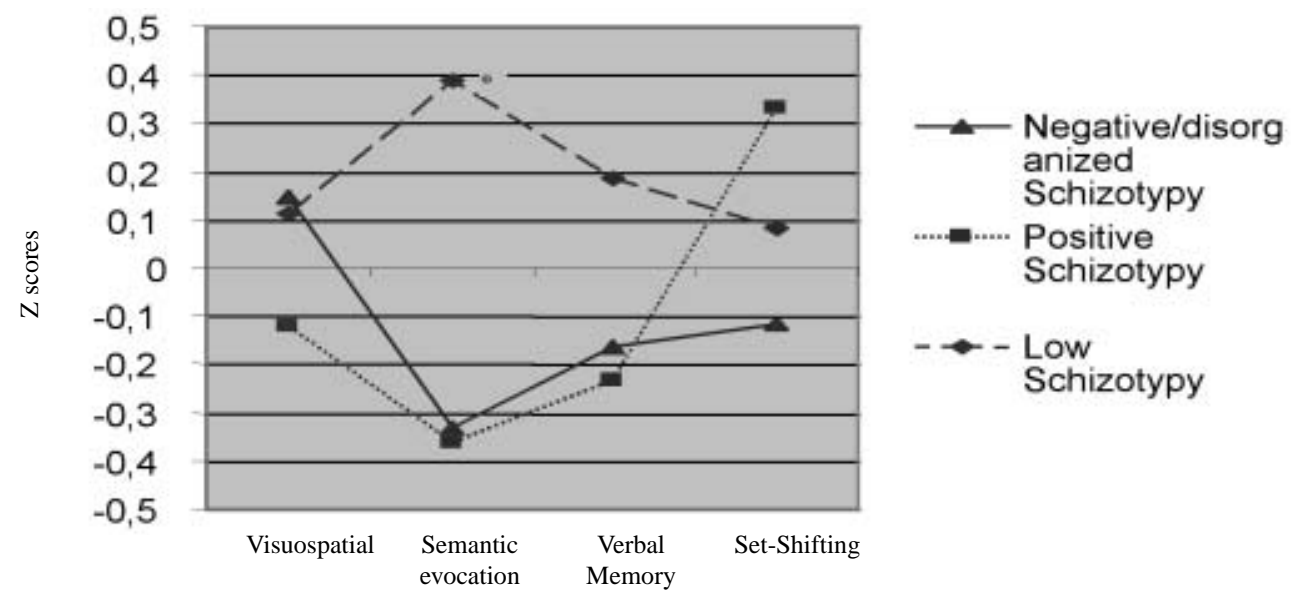

Figure 1. Mean values ( $\mathrm{Z}$ scores) of each neurocognitive factor for the schizotypy clusters in the non-clinical adult sample. $* \mathrm{p}<0.05$

Table IV

Zero-order correlations between neurocognitive factors and schizotypy dimensions.

\begin{tabular}{lccc} 
& Negative or interpersonal & Disorganized & Positive or cognitive-perceptual \\
\hline Visuospatial & 0.134 & 0.165 & -0.133 \\
Semantic evocation & $-0.355^{* *}$ & -0.203 & $-0.474 * *$ \\
Verbal memory & -0.105 & -0.019 & -0.091 \\
Set - shifting & -0.075 & -0.134 & -0.006 \\
\hline
\end{tabular}

$* \mathrm{p}<0.05 ; * * \mathrm{p}<0.01$.

\section{Discussion}

\section{Dimensions of schizotypy in the analyzed sample}

The cluster analysis carried out in the present study showed three different patterns of specific schizotypy features in a healthy adult community sample. A first cluster was defined by low scores on all schizotypy dimensions. This cluster contained the highest number of subjects from our sample $(63.2 \%)$, as expected in a non-clinical population. Secondly, a small cluster of predomi- 
nantly positive features emerged (13.2\%), and, finally, we found a third cluster with both negative and disorganized traits $(23.7 \%)$. Our results with an adult sample (mean age 30) highly resemble previous cluster studies that, almost exclusively (except for ${ }^{17,19}$ have been carried out with undergraduate students $16,18,20)$. This convergence seems to support the generalizability of the cluster solutions found in previous studies to the general population.

\section{The neurocognitive correlates of schizotypy}

This study also explored the neurocognitive correlates associated with schizotypy in non-clinical subjects. The comparison of the schizotypy clusters on neurocognitive performance showed a subtle difference in the "semantic evocation" factor. The positive and negative/disorganized schizotypy clusters showed poorer performance compared to the low schizotypy cluster. Correlational analysis also showed a negative relationship between the positive and negative schizotypal dimensions with the "semantic evocation" factor. Thus, contrary to our expectations, both approaches yielded the same results in this study. Therefore, in this sample of non-clinical young adults, we found support for the hypothesized relationship between individual differences on schizotypy and neurocognition variability but we were not able to show that the cluster of high negative schizotypy scorers has a worse neurocognitive functioning. It must be taken into account that the current sample size yielded schizotypy clusters with a relatively low number of subjects, something that may have reduced our ability to detect stronger differences.

The difference on semantic evocation seems to be consistent with the results of the cluster analysis by Barrantes-Vidal et al. ${ }^{17}$ with healthy adolescents, where the high schizotypy cluster (high on both positive and negative schizotypy) obtained the worst scores in verbal fluency, a task embedded in our semantic retrieval factor. The results are also consistent with those studies relating schizotypy dimensions with verbal fluency ${ }^{44-46}$. For instance, Krabbendam et al. ${ }^{47}$ found in non-clinical subjects from the general population that high scores on positive and negative schizotypy had poorer verbal fluency performance. However, other studies failed to find an association ${ }^{48,49}$.

These results are also in agreement with the consistent finding of impaired verbal fluency in the studies of cognition in schizophrenia ${ }^{50,51}$. Moreover, studies carried out in non-affected relatives of schizophrenia patients suggest verbal fluency as a vulnerability factor for schizophrenia ${ }^{52-55}$, as indeed has been confirmed in recent meta-analy$\operatorname{ses}^{56-58}$.

The association of both positive and negative schizotypy with semantic evocation may be related to the fact that verbal fluency performance involves several cognitive functions, such as verbal memory (previously associated with positive schizotypy ${ }^{46,59}$ ); executive functioning (mostly associated with negative schizotypy ${ }^{46,60}$; and psychomotor speed ${ }^{61}$. This may explain the lack of a specific association between this cognitive function and a particular schizotypy dimension, and points out the difficulty in linking symptom/trait dimensions with molar cognitive measures or constructs that are actually subserved by a number of components.

In addition, the fact that we only used the SPQ-B for assessing schizotypy traits may have had an impact on our ability to properly capture a group of anhedonic participants in 
the general population. Although the SPQ rates the nine symptoms of Schizotypal Personality Disorder, it does not adequately tap anhedonia, which is suggested to be the core feature of negative schizotypy. This might have also contributed to explain the lack of specificity found among positive and negative/disorganized clusters and semantic evocation and may explain the differences with other studies using the Chapman scales ${ }^{17,34}$, where anhedonia is a key component of negative schizotypy. In this respect, the slight difference in the construct of negative schizotypy may contribute to account for the lack of a differential relationship between neurocognition and positive and negative schizotypy, both when exploring dimensions by means of correlational analysis and high scoring subjects by means of cluster analysis.

\section{Acknowledgments}

Mari Aguilera thanks the Departament d'Universitats, Recerca i Societat de la Informació (DURSI) de la Generalitat de Catalunya for a predoctoral grant (2004 FI 00673) that made possible this study. This work was supported by grants from the Fundació La Marató de TV3 (014430/31) and the Fundació SENY (06). Supported by the Spanish Ministry of Health, Instituto de Salud Carlos III-RETIC RD06/0011/0007, Red de Enfermedades Mentales (REM-TAP Network).

\section{References}

1. Claridge G. Theoretical background issues. In: Claridge G, Claridge Gs Schizotypy: Implications for Ilness and Health. Oxford: Oxford University Press; 1997.
2. Meehl PE. Schizotaxia revisited. Arch Gen Psychiatry 1989; 46: 935-944.

3. Claridge G, McCreery C, Mason O, Bentall R, Boyle $\mathrm{G}$, Slade $\mathrm{P}$, et al. The factor structure of "schizotypal' traits: a large replication study. Br J Clin Psychol 1996; 35: 103-115.

4. Raine A, Reynolds C, Lencz T, Scerbo A, Triphon N, Kim D. Cognitive-perceptual, interpersonal, and disorganized features of schizotypal personality. Schizophr Bull 1994; 20: 191-201.

5. Stefanis NC, Hanssen M, Smirnis NK, Avramopoulos DA, Evdokimidis IK, Stefanis CN, et al. Evidence that three dimensions of psychosis have a distribution in the general population. Psychol Med 2002; 32: 347-358.

6. Stefanis NC, Smyrnis N, Avramopoulos D, Evdokimidis I, Ntzoufras I, Stefanis CN. Factorial composition of self-rated schizotypal traits among young males undergoing military training. Schizophr Bull 2004; 30: 335-350.

7. Vollema MG, van den Bosch RJ. The multidimensionality of schizotypy. Schizophr Bull 1995; 21: 19-31.

8. Vollema MG, Hoijtink H. The multidimensionality of self-report schizotypy in a psychiatric population: an analysis using multidimensional Rasch models. Schizophr Bull 2000; 26:565-575.

9. Liddle PF. Schizophrenic syndromes, cognitive performance and neurological dysfunction. Psychol Med 1987; 17:49-57.

10. Bilder RM, Mukherjee S, Rieder RO, Pandurangi AK. Symptomatic and neuropsychological components of defect states. Schizophr Bull 1985; 11: 409-419.

11. Grube BS, Bilder RM, Goldman RS. Meta-analysis of symptom factors in schizophrenia. Schizophr Res 1998; 31: $113-120$.

12. Miller DD, Arndt S, Andreasen NC. Alogia, attentional impairment, and inappropriate affect: their status in the dimensions of schizophrenia. Compr Psychiatry 1993; 34: 221-226.

13. Peralta V, de Leon J, Cuesta MJ. Are there more than two syndromes in schizophrenia? A critique of the positivenegative dichotomy. Br J Psychiatry 1992; 161: 335-343.

14. Smith DA, Mar CM, Turoff BK. The structure of schizophrenic symptoms: a meta-analytic confirmatory factor analysis. Schizophr Res 1998; 31: 57-70.

15. Wijers FWHM, Verhoeven WM, Tuinier S. The enigmatic phenotype: Relevant signs and symptoms in shizophrenia. Eur J Psychiat 2005; 19: 215-230.

16. Loughland CM, Williams, LM A cluster analytic study of schizotypal trait dimensions. Pers Indiv Differ 1997; 23: 877-883. 
17. Barrantes-Vidal N, Fañanás L, Rosa A, Caparrós B, Riba MD, Obiols JE. Neurocognitive, behavioural and neurodevelopmental correlates of schizotypy clusters in adolescents from the general population. Schizophr Res 2002; 61: 293-302.

18. Goulding A. Schizotypy models in relation to subjective health and paranormal beliefs and experiences. Pers Indiv Differ 2004; 37: 157-167.

19. Goulding A. Healthy schizotypy in a population of paranormal believers and experients. Pers Indiv Differ 2005; 38: 1069-1083.

20. Suhr JA, Spitznagel MB. Factor versus cluster models of schizotypal traits. I: a comparison of unselected and highly schizotypal samples. Schizophr Res 2001; 52: 231-239.

21. Dollfus S, Lombardo C, Benali K, Halbecq I, Abadie P, Marie RM, et al. Executive/attentional cognitive functions in schizophrenic patients and their parents: a preliminary study. Schizophr Res 2002; 53: 93-99.

22. Gur RE, Mozley PD, Resnick SM, Levick S, Erwin $\mathrm{R}$, Saykin AJ, et al. Relations among clinical scales in schizophrenia. Am J Psychiatry 1991; 148: 472-478.

23. Lykouras L, Oulis P, Daskalopoulou E, Psarros K, Christodoulou GN. Clinical subtypes of schizophrenic disorders: a cluster analytic study. Psychopathology 2001; 34 : 23-28.

24. Mohr PE, Cheng CM, Claxton K, Conley RR, Feldman JJ, Hargreaves WA, et al. The heterogeneity of schizophrenia in disease states. Schizophr Res 2004; 71: 83-95.

25. Morrison RL, Bellack AS, Wixted JT, Mueser KT. Positive and negative symptoms in schizophrenia. A cluster-analytic approach. J Nerv Ment Dis 1990; 178: 377-384.

26. Van der Does AJ, Linszen DH, Dingemans PM, Nugter MA, Scholte WF. A dimensional and categorical approach to the symptomatology of recent-onset schizophrenia. J Nerv Ment Dis 1993; 181: 744-749.

27. Williams LM. Cognitive inhibition and schizophrenic symptom subgroups. Schizophr Bull 1996; 22: 139-151.

28. Dollfus S, Everitt B, Ribeyre JM, Assouly-Besse F, Sharp C, Petit M. Identifying subtypes of schizophrenia by cluster analyses. Schizophr Bull 1996; 22: 545-555.

29. Aleman A, Hijman R, de Haan EH, Kahn RS. Memory impairment in schizophrenia: a meta-analysis. Am J Psychiatry. 1999; 156: 1358-1366.

30. Censits DM, Ragland JD, Gur RC, Gur RE. Neuropsychological evidence supporting a neurodevelopmental model of schizophrenia: a longitudinal study. Schizophr Res 1997; 24: 289-298.
31. Fioravanti M, Carlone O, Vitale B, Cinti ME, Clare L. A meta-analysis of cognitive deficits in adults with a diagnosis of schizophrenia. Neuropsychol Rev 2005; 15: 73-95.

32. Heinrichs RW, Zakzanis KK. Neurocognitive deficit in schizophrenia: a quantitative review of the evidence. Neuropsychology 1998; 12: 426-445.

33. Cornblatt B, Obuchowski M, Roberts S, Pollack S, Erlenmeyer-Kimling L. Cognitive and behavioral precursors of schizophrenia. Dev Psychopathol 1999; 11: 487-508.

34. Suhr JA, Spitznagel MB. Factor versus cluster models of schizotypal traits. II: relation to neuropsychological impairment. Schizophr Res. 2001; 52: 241-250.

35. First MB, Spitzer RL, Gibbon M, Williams JBW Structured Clinical Interview for DSM-IV Personality Disorder (SCID-II). Washington, DC: American Psychiatric Press, 1997.

36. Maxwell ME A Manual for FIGS. Bethesda, Maryland: Clinical Neurogenetics Branch, Intramural Research, National Institute of Mental Health; 1992.

37. WAIS-III Wechsler Adult Intelligence Scale (Third Edition) Administration and Scoring Manual, Psychological Corporation, San Antonio, USA. (Adaptación Española, 1999. TEA ediciones, S.A. Madrid), 1997.

38. Wechsler D Wechsler Memory Scale - Revised. Manual. New York: Psychological Corporation; 1987.

39. Cornblatt BA, Lenzenweger MF, Erlenmeyer-Kimling $\mathrm{L}$. The continuous performance test, identical pairs version: II. Contrasting attentional profiles in schizophrenic and depressed patients. Psychiatry Res 1989; 29: 65-85.

40. Spreen O, Benton AL. Comparative Studies of Some Psychological Tests for Cerebral Damage. J Nerv Ment Dis 1965; 140: 323-333.

41. Benton AL, Hamsher K Multilingual Aphasia Examination. Iowa City: AJA Associates, 1989.

42. Heaton R Wisconsin Card Sorting Test: Computer Version - 2. Research Edition. Odessa: Psychological Assessment Resources, Inc; 1981.

43. Raine A, Benishay D. The SPQ-B: A brief screening instrument for schizotypal personality disorder. Journal of Personality Disorders 1995; 9: 346-355.

44. Park S, Holzman PS, Lenzenweger MF. Individual differences in spatial working memory in relation to schizotypy. J Abnorm Psychol 1995; 104: 355-363.

45. Siever LJ, Koenigsberg HW, Harvey P, Mitropoulou V, Laruelle M, Abi-Dargham A, et al. Cognitive and brain function in schizotypal personality disorder. Schizophr Res 2002; 54: 157-167. 
46. Dinn WM, Harris CL, Aycicegi A, Greene P, Andover MS. Positive and negative schizotypy in a student sample: neurocognitive and clinical correlates. Schizophr Res 2002; 56: 171-185.

47. Krabbendam L, Myin-Germeys I, Hanssen M, van Os J. Familial covariation of the subclinical psychosis phenotype and verbal fluency in the general population. Schizophr Res 2005; 74: 37-41.

48. Kiang M, Kutas M. Abnormal typicality of responses on a category fluency task in schizotypy. Psychiatry Res 2006; 145: 119-126.

49. Vollema MG, Postma B. Neurocognitive correlates of schizotypy in first degree relatives of schizophrenia patients. Schizophr Bull 2002; 28: 367-377.

50. Allen HA, Liddle PF, Frith CD. Negative features, retrieval processes and verbal fluency in schizophrenia. $\mathrm{Br}$ J Psychiatry 1993; 163: 769-775.

51. Joyce EM, Collinson SL, Crichton P. Verbal fluency in schizophrenia: relationship with executive function, semantic memory and clinical alogia. Psychol Med 1996; 26: $39-49$.

52. Chen EY, Hui CL, Dunn EL, Miao MY, Yeung WS, Wong CK, et al. A prospective 3-year longitudinal study of cognitive predictors of relapse in first-episode schizophrenic patients. Schizophr Res 2005; 77: 99-104.

53. Gilvarry CM, Russell A, Jones P, Sham P, Hemsley D, Murray RM. Verbal fluency in patients with schizophrenia and affective psychoses and their first-degree relatives. Psychol Med 2001; 31: 695-704.

54. Hughes C, Kumari V, Das M, Zachariah E, Ettinger $\mathrm{U}$, Sumich A, et al. Cognitive functioning in siblings discordant for schizophrenia. Acta Psychiatr Scand 2005; 111: $185-192$.

55. Kremen WS, Seidman LJ, Pepple JR, Lyons MJ, Tsuang MT, Faraone SV. Neuropsychological risk indicators for schizophrenia: a review of family studies. Schizophr Bull 1994; 20: 103-119.

56. Snitz BE, Macdonald AW, 3rd, Carter CS. Cognitive deficits in unaffected first-degree relatives of schizophrenia patients: a meta-analytic review of putative endophenotypes. Schizophr Bull 2006; 32: 179-194.

57. Szoke A, Schurhoff F, Mathieu F, Meary A, Ionescu $\mathrm{S}$, Leboyer M. Tests of executive functions in first-degree relatives of schizophrenic patients: a meta-analysis. Psychol Med 2005; 35: 771-782.
58. Trandafir A, Meary A, Schurhoff F, Leboyer M, Szoke A. Memory tests in first-degree adult relatives of schizophrenic patients: a meta-analysis. Schizophr Res 2006; 81: 217-226.

59. Keefe RS, Silverman JM, Mohs RC, Siever LJ, Harvey PD, Friedman L, et al. Eye tracking, attention, and schizotypal symptoms in nonpsychotic relatives of patients with schizophrenia. Arch Gen Psychiatry 1997; 54: 169-176.

60. Raine A, Sheard C, Reynolds GP, Lencz T. Prefrontal structural and functional deficits associated with individual differences in schizotypal personality. Schizophr Res 1992; 7: 237-247.

61. van Beilen M, Pijnenborg M, van Zomeren EH, van den Bosch RJ, Withaar FK, Bouma A. What is measured by verbal fluency tests in schizophrenia? Schizophr Res 2004; 69: 267-276.

62. Eckblad M, Chapman LJ. Magical ideation as an indicator of schizotypy. J Consult Clin Psychol 1983; 51: 215-225.

63. Claridge G, Broks P. Schizotypy and hemisphere functions: I. Theoretical consideration and the measurement of schizotypy. Pers Indiv Differ 1984; 5: 633-658.

64. Chapman LJ, Chapman JP, Raulin ML. Scales for physical and social anhedonia. J Abnorm Psychol 1976; 85: 374-382.

65. Eckblad MB, Chapman LJ, Chapman JP, Mishlove M The Revised Social Anhedonia Scale. Madison: Unpublished test, 1982.

66. Mason O, Claridge G, Kwapil TR. New scales for the assessment of schizotypy. Pers Indiv Differ 1995; 18: 7-13.

67. Raine A. The SPQ: a scale for the assessment of schizotypal personality based on DSM-III-R criteria. Schizophr Bull 1991; 17: 555-564.

68. Chapman LJ, Chapman JP, Raulin ML. Body-image aberration in Schizophrenia. J Abnorm Psychol 1978; 87: 399-407.

Address for correspondence:

Maria del Carmen Aguilera Ruiz

Unitat d'Antropologia, Dept. Biologia Animal, Facultat de Biologia, Universitat de Barcelona; Av. Diagonal 645, 08028, Barcelona, Spain.

Email: mari.aguilera@ub.edu

Telephone number: +34934021461

Fax number: +34934035740 